Desde o nascimento, o

dbjeto está ligadb à

angústia. Ainda que haja

dessimetria em relação à

relação cam o objeto, é, no

entanto, a angústia que

liga antes de mais nada a

mãe e a criança. Do ponto

de vista da criança, presa

em seu narcisismo, 0

exterior é impensável. Do

ponto de vista da mãe, a

crianca só é pensável na

medida em que ocupa o

lugar de algo além de si

mesmo. Em conseqüência,

a criança encontra-se logo

de início perdida como

dojeto da perda de sua

mãe. A angústia cria o

objeto, e poderíamos

quase dizer que não há

outro abjeto além daquele

que toma consistência pelo

fato de tomar a angústia

menos forte. É preciso,

portanto, perceber um

certo tipo de ilusão para

que a criança apreenda o

mundo e um certo tipo de

desilusão para que a

criança tome consistência

real para sua mãe.

Angústia; dojeto; ilusão;

recalque; falo; castração

IMPOSSIBLE WITHOUT

ANXIETY

The object is linked to

anxiety as soon as birth.

Though there is a

dissymetry towards the

relationship to the doject,

meanwhile anxiety links

mother and child. Fram the

child's point of view, taken into his narcissism, atside carmot be thought. Fram the mother's point of view, the child can anly be

thought as samebody taking the place of samething else than himself. Consequently, the child is therefore lost as andoject of the loss of his mother. Anxiety creates the object, and we could nearly say that there is no other object than the ane taking consistence while lowering anxiety. There is a necessity to envisage a certain type of itlusion so that the child dbe able to perceive the world and a certain type of disillusioment so that the dild takes a real

consistence for his mother.

Anxiety; object; illusion;

repression; phallus;

castration

\section{NÃO SEM ANGÚSTIA}

\author{
Robert Lévy
}

Tradução: Inesita Machado

"O que nos incomoda aqui é manifestamente uma dificul dade no desenvol vimento de nossa teoria caspulsc̃es" (Freud, 1925-6, p. 48)

$\mathrm{P}_{\mathrm{r}}$

a existência de um objeto para uma criança é ao mesmo tempo supor que um exterior, um mundo exterior a si mesma, tem consistência. Ora, a criança, desde seu nascimento, encontra-se com o mundo exterior, segundo Freud, em tal relação que "o nascimento não é vivido subjetivamente como separação da mãe, pois esta é, enquanto objeto, completamente desconhecida do feto absolutamente narcísico" (Freud, 1925-6, p. 54) .

Esse parece-nos ser o único ponto de apoio a partir do qual é possível perceber com seriedade toda noção de relação com algum objeto, seja ele parcial, ou com qualquer outro, seja ele escrito com um a minúsculo ou maiúsculo (A) .

Esse ponto consiste em enunciar, como o faz Freud, que a criança "nasce de mãe desconhecida" e que sua chegada ao mundo é marcada antes de tudo pela angústia, não que esta seja o resultado de uma operação, mas que esta an-

Doutor em Psicologia, professor em Paris 13, psicanalista membro de Analyse Freudienne. 
gústia é aquilo que, antes de mais nada, funda o lugar do outro para toob ser falante.

Do lado da mãe, Freud insiste em nos mostrar que o mesmo acontece, já que "a primeira experiência de angústia, pelo menos no homem, é o nascimento, que significa objetivamente a separação da mãe e poderia ser comparada a uma castração da mãe (segundo a equação criança = pênis)" (Freud, 1925-6, p. 54) . Portanto, a criança é antes de tudo uma castração da mãe e um dbjeto de angústia.

De acordo com essa concepção, a criança não é separada de sua mãe em seu nascimento, pois não existe como tal, enquanto a mãe está bem separada (castrada) da criança. Esta nasce, portanto, primeiramente sob o signo de uma separação geradora de angústia para sua mãe enquanto "objeto pênis" perdido. Assim, a criança chega sob o signo da deceppção para sua mãe, e isto ainda que as aparências idílicas nos enganem freqüentemente. O que chamamos de depressão pós-parto constitui a prova e a lembrançadissso.

Talvez a ambigüidade em tomo deste "maravilhoso nascimento" seja relativa ao fato de que confundimos objeto de amor e dbjeto da pulsão. Uma sábia discussão foi realizada durante muito tempo sobre o equívoco da palavra "luto"; i esta se refere a um certo tipo de relação com o dbjeto.

Inicialmente, ainda que haja dessimetria em relação à relação com o objeto, aquilo que liga os dois protagonistas, mãefilho, é a angústia. Do ponto de vista da criança, o exterior é impensável, porque este é totalmente narcísico. Do ponto de vista da mãe, este fi 7ho, "saído de si mesma", só é pensável enquanto ocupando o lugar de algo diferente de si mesmo, que Freud qualificour de "pênis".

Conseqüentemente, a criança encontra-se logo de início perdida como objeto da perda de sua mãe. Portanto, ela já está perdida para ela, antes mesmo de chegar ao mundo, o que não nos explica de que modo a criança pode reconhecer algo além da angústia que ela experimenta e daquilo que a suspende. Em outros termos, se a criança pode faltar à sua mãe porque esta não tem pênis, como pode a mãe faltar à criança se esta ainda não tem objeto?

\section{A ANGÚSTIA CRIA O OBJETO}

É a angústia que, para os dois, cria o dbjeto, e poderíamos até mesmo dizer que não há outro objeto além daquele que toma 
consistência pelo fato de tomar a angústia menos forte. É o mesmo que dizer que o objeto não existe enquanto tal, a não ser a cada etapa do desenvolvimento do sujeito, durante o qual encontramos um certo tipo de relação do sujeito, com o mundo em que o dbjeto é uti i izadb para mascarar a angústia, para vir ocupar seu ligar.

A mãe não pode, portanto, estar presente ou ausente para a criança a não ser de modo secundário, isto é, ocupando o lugar da presença que suspende a angústia ou da ausência que a repõe em ação.

A dialética presença/ausência só poderá ter o efeito de uma simbolização se, e scmente se, puder realizar seu trabal ho de acomodação à perda fundamental. Se podemos falar em "perda fundamental" , é porque Lacan introduziu a idéia, totalmente nova, no pós-freudismo, de que nunca houve um objeto que tenha satisfeito a pulsão, o que significa que aquil lo que nos interessa a partir daí é saber de que modo podemos acomodar-nos a uma não satisfação fundamental, e não à perda de um objeto, qualquer que seja ele, que permanece então como uma modalidade secundária.

Trata-se, portanto, de uma crítica de Lacan ao que Freud pôde perceber como "dbjeto perdido da primeira satisfação", que podemos considerar como mítica.

A partir daí, nem todo objeto pode ser considerado a não ser como substituto daquele que, justamente, nunca satisfez a pulsão, e não o inverso, isto é, como objeto que substituiria o inicial prearsor do gozo total.

Isso nos leva a considerar que o mundo só tem existência para a criança como "ilusão", e, de certa forma, Freud o sugere, lembrando que "o objeto matemo psíquico substitui para a criança a situação fetal biológica, e isto não é motivo para esquecer que, na vida intra-uterina, a mãe não era um dojeto para o feto e que então não havia objeto" (Freud, 1925-6, p. 63) .

Portanto, é com a "ilusão" que a criança apreende o mundo, e não há nenhum outro meio de distinguir o que foi feito da realidade, a não ser por aquilo que Winnicott (1969) chamou de desilusãol, isto é, o exercício que consiste no fato de que a realidade possa não corresponder à alucinação surgida do desejo.

Com essa concepção, confrontamo-nos novamente com algo que também diz respeito à mãe, pois poderíamos aplicar esta necessidade de desilusão àquilo que uma mãe deve realizar para si mesma se ela quiser que seu fi tho adquira uma consistência real.

Portanto, recaímos, inevitavelmente, sobre esta famosa equação, pênis = criança, de que podemos nos perguntar de que modo 
ela pôde constituir-se para a mãe. Este problema é absolutamente delicado, pois, como observa Freud a respeito da angústia: "Estaria estabelecido que a angústia é o único motor do recalque (ou da defesa) ? Se pensarmos nas neuroses das muIheres, será preciso questionar este ponto, pois, se podemos constatar a existência do complexo de castração nas mulheres, não poderíamos entretanto falar de uma angústia de castração no caso em que a castração já esteja realizada" (Freud, 19256, p. 45) .

Acompanhando Freud, como poderíamos nos angustiar com aquilo de que já fomos castrados? No entanto, este ponto é crucial para Freud.

É a angústia que cria o recalque, e não o inverso, como ele havia considerado inicialmente. Então, em que consiste esta primeira experiência de angústia, já que, finalmente, é isto, esó isto, que traça o lugar da construção de um possível objeto que viria aliviar ou anular esta mesma angústia. Assim, o "seio nutriente da mãe é para a criança o primeiro objeto erótico; o amor apóia-se sobre a satisfação da necessidade de alimento. No início, certamente a criança não diferencia o seio que lhe é oferecido de seu próprio conpo. É porque a criança percebe que 0 seio lhe falta constantemente que ela o situa fora e o considera a partir de então como um objeto, que de um lado é carregado do investimento narcísico primitivo e que se completa em seguida tomando-se a pessoa materna" (Freud, 1938-40, p. 60).
No entanto, até 1938, data da redação do compêndio de psicanálise, Freud ainda traz a necessidade do filogenético: "O fundamento filogenético predomina a tal ponto nos fatores pessoais, acidentais, que pouco importa que a criança tenha realmente mamado em sua mãe ou que ela tenha sido alimentada por mamadeira sem jamais conhecer os ternos cuidados matemos. O deservolvimento é semelhante nos dois casos" (Freud, 1938-40, p. 60) .

O mesmo se dará com a castração, "o mais forte traumatismo de sua jovem existência" (Freud, 193840, p. 62) , para a qual Freud utilizará o mesmo recurso filogenético desenvolvido muma pequena nota de rodapé: "É possível que o extraordinário terror provocadb por esta ameaça seja em parte devido a um traço mnemônico filogenético, lembrança da época pré-histórica em que o pai, com ciúmes, tirava os órgãos genitais de seu fil lho quando o considerava como um rival junto a uma mulher" (Freud, 1938-40, p. 62, n. 1) . Angústias de separação e angústia de castração têm uma seqüência lógica?'.

É o mesmo que dizer o quanto Freud encontra-se perturbado por uma teorização da relação com o dojeto, com sua constituição e com a dificuldade de aí introduzir umpai.

Observemos, em todo caso, que algo não se pode estabelecer para a criança apenas porque há uma reação à ausência, ausência daquil lo que satisfaz todas as suas necessidades sem demora, e não o inverso.

o único ponto forte sobre o qual iremos permanecer constitui a 
idéia de que este homenzinho encontra-se, desde seu nascimento, numa total alienação ao outro, sendo ele mesmo objeto da angústia de separação de sua mãe. Mas esta criança, "totalmente narcísica", só tem relação com o outro na medida em que é completamente dependente. A conseqüência disso é que ela só amará dentro da categoria do tipo narcísico mais absoluto. Segundo Freud, amamos de acordo com quatro tipos narcísicos:

a) was man selbst ist (sich selbst) -> aquilo que somos;

b) was man selbst war -> aquilo que fomos;

\& has man selbost seinmöchte -> o que gastaríamos de ser;

d die person, die ein tuldes eigenen selbst war -> a pessoa que foi uma parte de seu próprio corpo.

\section{UMA MÃE NEM BOA NEM MÁ}

Dentro dessas diferentes escoIhas de abjeto, é o primeiro que se resume a si mesmo (: ama-se a si mesmo) . Encontramos aí o sich sellast (si mesmo) originário do narcisismo. Sich selbst (si mesmo) não é mais do que este estado de tensão levado a zero pela intervenção do outro: a mãe, para Freud, a boa ou má mãe, para Melanie Klein, ou a mãe suficientemente qualquer, "good enough mother", para Winnicott (1975) , que rebatiza, portanto, este outro do qual a criança é totalmente dependente ${ }^{3}$. De seu lado, ele precisa que não se trata de falar das mães enquanto pessoas reais com os bebês, camo se elas pudessem realmente ser boas. Winnicott (1975) introduz esse "suficientemente" para mudar a perspectiva e deixar a capacidade às mães, ou substitutas que cuidam dos bebês, de não serem nem boas nem más, mas simplesmente um falho "alguém" . Com uma mãe suficientemente boa, o bebê terá de se adaptar, arranjar-se com aquilo que nelas "falha", e, conseqüentemente, ele não terá attro reariso a não ser a tolerância à finustração.

Mas a resistência dos analistas de crianças fez com que "good enough mother" tenha infelizmente passado para a contra-mão com o uso psicanalítico. Efetivamente, este "suficientemente" indica voluntariamente uma ambigüidade, pois se trata ao mesmo tempo de uma satisfação e de um limite que não deve ser transposto, istoé, um "suficientemente alguém" que permitirá, portanto, conduzir a criança "à ilusão de que essa mãe suficientemente boa seja o seio bom" (Wimnicott, 1929, p. 74), diz Winnicott, que situa o lugar do analista exatamente nesse ponto: "De um modo análogo na análise, o analista só poole ser sempre falho" (Winnicott, 1929, p. 74). Para Winnicott, trata-se de acabar com o sentimentalismo e a idealização da noção de boa e de má mãe kleiniana, e, acima de tudo, de tornar "pensável" o que permite à criança passar do estado de união narcísica com sua mãe para um outro estado em que elas possam estar "em relação" com o mund exterior. "Evidentemente, não é o objeto que é transicional. O dbjeto representa a 
transição da criança pequena que passa do estado de união com a mãe ao estado em que ela está em relação com ela enquanto algo de exterior e de separado" (Winnicott, 1975, p. 26) . Este espaço de transição é uma área de i lusão que implica que "o indivíduo só se commica com um mundo que ele criou, e as pessoas do ambiente só se comunicam com o indivíduo sob a condição de poderem criá-1o" (Winnicott, 1929, p. 80) .

Para Winnicott, qualquer relação com o mundo só é possível na medida em que ele passa por essa dimensão de ilusão vinda da adaptação da criança pequena ao fato de que sua mãe não seja nem boa, nem má, isto é, que ela não a possa completar permanentemente...

\section{FRUSTRAÇÃO， PRIVAÇÃO， CASTRAÇÃO}

Avançamos até aqui na tentativa de situar a relação mãe/filho e seus objetos, sem que tenha aparecido no horizonte algo de pai. Somos dorigados a constatar que não se trata de pai inicialmente em nenhum lugar, a não ser sob a forma de frustração... privação... castração, isto é, do pai, pode existir apenas uma função sob a forma de um corte, de uma ruptura, de uma separação da tendência matema à unificação e ao narcisisismo primário. Efetivamente, o pai está implícito na equação freudiana de início, pênis = criança, que introouz o desejo da mãe em relação à criança, ao pai e ao falo. Nesta dimensão, a mãe só deseja um fil ho na medida em que, menina, "ela esperou este fillho do pai". Mas, uma vez mãe, há uma má distribuição de cartas, pois o falo continua a faltar. Daí este momento maravi lhoso desta plenitude de que falam as mulheres grávidas, durante o qual nada se passou ainda, pois esta criança "elas a têm realmente no ventre" durante nove meses antes de estarem confrontadas com o real do nascimento que faz desabar este belo edifício de completude imaginária, precipitando-as novamente na perda.

Assim, essa díade mãe/filho partilha um engano. A criança é o objeto enganador para sua mãe, e a mãe, engano de satisfação total para seu filho. Mas este será tanto um engano para sua mãe, que ele terá a impressão de satisfazê-la e, por meio dessa i lusão, dbterá de novo sua presença. Há a necessidade de estabelecer um processo de ilusão-desilusão, pois o dojeto transicicional no centro deste trabalho é "virtualmente um falo matemo" (Winnicott, 1969, p. 185) que dispensa falar sobre o que falta à mãe e obstrui materialmente a falta que deixa a ausência. Este dojeto, em seu traba- 
Iho de ilusão-desilusão, fica preso, portanto, na simultaneidade de sua criação pela criança e de sua caução pelo ambiente. Mas pode haver negação da separação, que passibilita assimparar este processo para evitar a desilusão. Esta negação inicial adquire consistência primeiramente do desejo da mãe que mantém seu fitho no lugar de falo para que ele permaneça como esse "tudo" de que ela foi, desde a origem, castrada.

Isso constitui, sem dúvida, as premissas desse acordo imaginário, contato que já tende a fazer com que se acredite que um, a criança, passa trazer ao autro, a mãe, o que ela não tem. É neste mesmo lugar de engano, por excelência, que o dbjeto fetiche pode vir mais tarde a selar, nos termos de um contrato perverso, a eleição de um objeto oculto do sexo que esta mãe não tem. Fetiche ou "tapa-sexo", objeto imaginário que passa à representação real num segundo tempo: tempo necessário para o encontro com a eleição do abjeto fetiche como exclusivo...

Mas existem outras probabilidades do objeto na construção do sintoma em relação ao Falo. Tratase da fobia, ou mais exatamente, do abjeto föbico. Este último, talvez mais do que qualquer outro, situa o lugar do dbjeto enquanto visado pela angústia e faz a demonstração de que sua função é a de sustentar a relação com o desejo sob a forma da angústia. No limite poderíamos dizer que "a angústia é o último modo, radical, sob o qual o sujeito continua a sustentar, ainda que de modo insustentável, a relação com o desejo" (Lacan, 1991, p. 424) . 
O ANALISTA E SUA RESPONSABILIDADE

De certo modo, esse último ponto traça definitivamente aquilo que pode ser o lugar do analista e sua responsabilidade. Efetivamente, se pensarmos que sua função é permitir à criança desalojarse de seu lugar de objeto para que ela advenha como sujeito, a partir daí seu lugar tem algo de impostura, pois ela só pode tratar com a angústia, e não sem ela, na medida em que a angústia é o modo radical e sob o qual é mantida a relação com o desejo.

Portanto, uma impostura enquanto "fazer coma angústia" exclui a priori db desejo de analista sua conversão em figura parental ideal, lugar para o qual o convidam incessantemente a criança e o social. A análise de crianças só pode, portanto, inscrever-se a partir da falha em relação ao disarso médico que, como tal, visa a amular qualquer angústia, com o suposto benefício de uma fel icidade enfim (re) encontrada, de que o analista sabe que o preço a pagar seria a interdição de pensar.

"Fazer com a angústia" não pode igualmente estar na ordem de um desejo de saber que conduz mais à doservação. E, se Freud encorajou seus alunos a "doservar" as crianças diretamente, ele concluiu, no entanto, que isto não poderia servir de guia para uma análise e que, no fundo, Hans nada havia the ensinado de novo em relação àquilo que ele já havia avido da parte de suas pacientesadiltas.
Freud, S. (1925-6). Inhibition, symptâne et angoisse. Paris: PUF, 1986. (1938-40) . Abrégé de psychanalyse.

Paris: PUF, 1973.

Iacan, J. (1991) . Ie transfert. Paris: Sail.

Winnicott, D.-W. (1929). Lettres vives. Col. NRF. Paris: Gallimard. (1969) . De la pédiatrie à la psychanalyse. Paris: Payct.

(1975) . Jeu et réalité. Col. NRF. Paris: Gallimard.

NOTAS

1 "Désill lusionnement" utilizado pelo autor refere-se ao termo em inglês "bisillusioment" encontrado na dbra de Winnicott (N.do T. ) .

2 "Le Mbi a été préparé à la castration par des pertes de l' dojet régul ièrement répétées.."" (Freud, 1938-40, p. 54). (O Eu foi preparado para a castração pelas regularmente repetidas perdas do dojeto... .)

${ }^{3}$ Preferimos a tradução do inglês "good enough" por "suficientemente alguma", como muito corretamente estabelecido por M. -C. Panzani.
Recebidb em janeiro/2004. Aceito em março/2004. 